
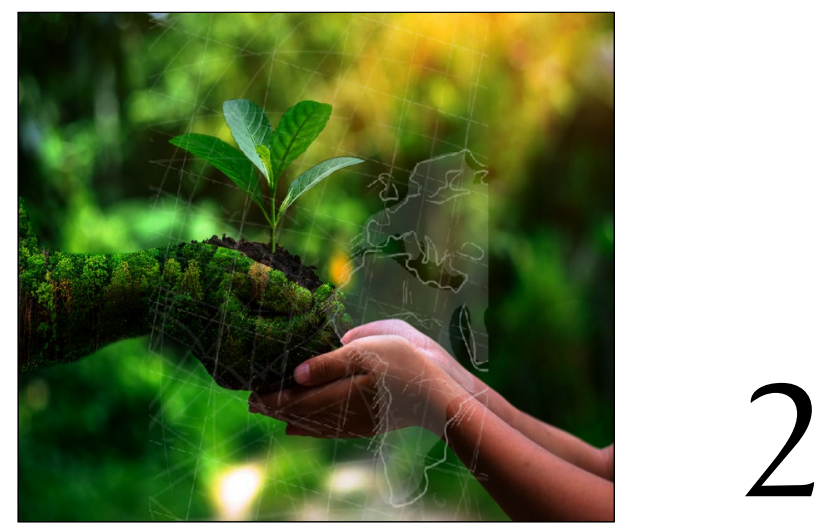

\title{
ECOLOGICAL INFRASTRUCTURE AS A BASIS FOR THE AFRICAN WELLBEING ECONOMY
}

\author{
Kristi Maciejewski and Scott Drimie
}

\section{Introduction}

Sustainable development relies on a balanced relationship between addressing social and economic growth within the boundaries of the environment. The environment not only presents the foundation that creates and sustains life on earth but also provides the assets upon which to build a country's economic development. The production of food, provision of water and natural resources, regulation of climate and purification of air rely on the sustainable management of the natural world we live in.

Natural resources, however, are limited and decreasing rapidly. If they are not sustainably managed, the system in which they are embedded will collapse. The commercial agriculture sector, for example, which forms part of the food system, contributes nearly one-third of all anthropogenic greenhouse gas emissions, causing rapid deforestation, soil degradation, and massive biodiversity loss. These affect the Earth system functioning to a degree that threatens the long-term sustainability 
of the system. Development decision-makers need to take cognisance of the ecological system, ecological functions and processes and treat these common resources sustainably.

Put simply, environmental resources are required to support economies to grow, while also meeting the needs of society. The imperative, therefore, is for sustainable development that is not only economically and socially sustainable, but also environmentally sustainable. It is useful to consider this through the lens of human wellbeing: if society collapses, the wellbeing of countless individuals will be reduced, if the economy collapses that society will be significantly weakened, and if the environment collapses, the economy will be massively damaged. For human wellbeing to be maximised, environment, economy and society must be in the best possible state without compromising each other.

A powerful way of approaching this is to consider that ecological infrastructure needs to be at the forefront when thinking about the wellbeing economy. Ecological infrastructure is the nature-based equivalent of built or hard infrastructure. For example, instead of using conventional engineering solutions, such as water infiltration and drainage systems, rather restore the wetlands and mangrove forests that naturally provide these services. Nature-based solutions offer a more sustainable way of living, reducing the impact on the environment, and provide multifunctional solutions to several challenges which are also more cost-effective (Nesshöver et al., 2017).

In Africa, economic growth remains heavily dependent on natural resources. Yet the significant degradation of the natural environment coupled with the impacts of climate change continue to impede sustainable human development. Achieving pro-poor environmentally sustainable economic growth will require an enhanced understanding of how sustainable use of natural resources can help reduce poverty and support economic growth. In this chapter, we illustrate the importance of maintaining and strengthening a resilient social-ecological system approach as the foundation of wellbeing in Africa.

\section{A social-ecological systems approach to development}

The ecological infrastructures underpinning sustainable development are comprised of threatened ecosystems and limited natural resources and, therefore, need to be managed as common-pool resources. The sustainable use of ecosystems relies on cooperation and trust between stakeholders. Understanding that resources need to be harvested sustainably, overharvesting by one actor means there is less of the resource available for others. In a social-ecological system, two social actors sharing one ecological resource implies competition that can lead to 
overharvesting (Ostrom, 1990). Social-ecological systems are systems that include social, economic, and ecological elements as well as interactions between them (Cumming et al., 2015). The concept of a social-ecological system is useful because it explicitly implies that stakeholders and related institutions are part of a cohesive whole, the system.

Many ecosystems and the services they provide are perceived as public goods and are not recognised in planning processes. For example, building infrastructure to provide people with water for irrigation is crucial for economic growth, for alleviating poverty and attaining many of the Sustainable Development Goals (SDGs). However, this infrastructure, especially dams, has impacts on aquatic ecosystems, and by altering the flow of water, sediment and nutrients can weaken the ecosystem services on which the communities depend (McCartney et al.,2005).

It is sometimes necessary to modify ecosystems to facilitate socio-economic development. However, this does not have to mean the degradation of ecosystems. In considering the value of ecosystems, the intent is to identify interventions that offer people long-term sustainable solutions to improve their livelihoods. For instance, by focusing more on ecosystem services, development decisions can incorporate human perceptions - the values people place on different parts of the landscape that tend to go unrecognised. Ecosystem services are the benefits people receive from nature. Tangible benefits include supplies of food and fresh water, flood mitigation and improvements to water quality. Less tangible benefits include contributions to cultures. This concept (ecosystem services) also offers a useful link between ecological and economic perspectives; by achieving a compromise between different approaches (valuation and markets versus biodiversity and system functioning), it helps ecologists and economists to communicate (Daily et al., 2000).

As an example, the Working Wetland Potential (WWP) is a pragmatic socialecological systems approach that contextualises the provisioning ecosystem services of a wetland in terms of agriculture, without undermining the ecological infrastructure (McCartney et al., 2005). WWP uses a multi-criteria analysis that integrates the biophysical and socio-economic aspects of wetland use to provide an initial assessment of the suitability of a wetland for agriculture. This assessment can then be used to identify, organise and analyse complex factors, which in this case links people, agriculture and wetlands to develop wetlands sustainably.

Africa faces enormous challenges in relation to environmental management, and equally huge opportunities for 'doing things better' (United Nations Environment Programme [UNEP], 2016b). Building a wellbeing economy across the continent depends explicitly on the protection and integrity of the natural resources that are critical life-support systems for sustained human wellbeing. Without the 
understanding that clean and healthy air, water, land and biodiversity are necessary to support a transformation to a wellbeing economy, an integrated, prosperous and peaceful region, resilient to future shocks, will likely remain a pipe dream.

\section{The current state and trends in Africa}

According to the sixth edition of the Global Environment Outlook (GEO-6), Africa has the potential to significantly contribute to the world economy and ensure healthy living conditions for all its denizens (UNEP, 2016b). Africa, the second largest continent in the world, has a landmass of 30 million $\mathrm{km}^{2}$. Twenty-two percent of this land area consists of forests and woodlands, 43 percent is classified as desert, and 21 percent is suitable for cultivation. According to the United Nations Economic Commission for Africa (UNECA), by 1999, it was estimated that about 32 percent (200 million ha) had already been cultivated (UNECA, 2011). At the same time, about 30 percent of the total land area ( 892 million ha) was being used as permanent pasture. This significant loss in biodiversity does not necessarily result in poverty alleviation or an increase in human wellbeing; in fact, the opposite has occurred. Even though the continent has abundant agricultural resources, according to the Africa Human Development Report 2012, millions of people remain hungry and malnourished (United Nations Development Programme [UNDP], 2012). This was reiterated in the Africa Regional Overview of Food Security and Nutrition (Food and Agriculture Organization of the United Nations [FAO], (2017). This is largely a result of uneven local food production and distribution and chronically deficient diet. The UNDP mentions that 'Africans have been trapped by hunger for decades, with millions consuming staple foods deficient in the micronutrients needed to sustain child growth and adult productivity. Hunger also eviscerates society by increasing disease, mortality and disability' (UNDP, 2012:15).

The majority of people in Africa (approximately 85 percent) live in rural areas and are engaged in agricultural activities, with farming making up the main source of their livelihoods (World Bank, 2009). Agriculture plays a major role in the continent's economy, employing nearly 70 percent of Africa's population and generating 30 percent of gross domestic product (GDP) (UNEP, 2016b). Farming productivity, however, is largely driven by precipitation, which has been decreasing over the African continent. Over the past few decades, the northern regions of North Africa have experienced a strong decrease in the amount of precipitation in winter and early spring. The Sahel has experienced an overall reduction in precipitation over the course of the twentieth century. The same is found in eastern Africa where rainfall has decreased over the past three decades, potentially due to an increase in convection and precipitation over the tropical Indian Ocean (Funk et al., 2008). Over southern Africa, a reduction in late summer precipitation 
has been reported over the western parts, extending from Namibia, through Angola, and towards the Congo, associated with an upward trend in tropical Indian Ocean sea surface temperatures. Changes in the distribution and magnitude of extreme rainfall events observed in parts of Africa are associated with both climate and variability (Williams, Kniveton \& Layberry, 2010), where Africa's near-surface temperatures have increased by $0.5^{\circ} \mathrm{C}$ over the past 50 to 100 years.

Land cover and land-use changes in Africa are largely driven by population growth, urbanisation and investments in large-scale commercial agriculture. Large tracts of natural land, including forests, are continuously being cleared for agriculture. For example, the Mwekera forest in Zambia has undergone significant deforestation over time with estimates ranging from 250000 to 900000 ha per year (Shawa, 2010) with the increase in demand for firewood and cultivable land (UNEP, 2016b). The trend of decreasing forest cover has also been recorded throughout north, west, central, east and southern Africa between 1950 and 2015 (FAO, 2018). These forests are projected to continue shrinking, declining to less than 600 million ha by 2050 due to the rising population and growing demand for firewood. More than 50 million ha of forests have been lost in Africa between 1990 and 2000, representing an average deforestation rate of nearly 0.8 percent per year (UNECA, 2011). Forests play an important role in the carbon cycle. When forests are cut down, not only does carbon absorption cease, but the carbon stored in the trees is released into the atmosphere, increasing carbon dioxide concentration levels.

Land degradation is a serious threat in Africa, with about $500000 \mathrm{~km}^{2}$ of land estimated to be degraded due to soil erosion, salinisation, pollution and desertification (UNEP, 2013). This is largely driven by deforestation, forest fires, over-cultivation, inefficient irrigation practices, overgrazing, overexploitation of resources, including mining, as well as climate change (UNEP, 2016b). Land degradation reduces agricultural productivity, directly impacting on food availability, nutrition and human health. Land degradation in drylands can result in desertification. The desert lands of the Sahara, Namib, Kalahari, and the drylands of northern Kenya, southern Ethiopia and Somalia cover around 40 percent of Africa's land surface area (Jones et al., 2013).

The unreliable rainfall patterns in Africa coupled with the decrease in precipitation over time also affects the availability of freshwater. Most countries in the arid and semi-arid north and southern Africa sub-regions have lower per person internal renewable freshwater levels than the rest of the continent. With an average annual per-person consumption of $31 \mathrm{~m}^{3}$, Africa uses much less water than regions such as North America, which consumes $221 \mathrm{~m}^{3}$ per person per year (UNEP, 2010). 
The quantity of water available in Africa is variable, depending on the climatic and geological setting. Africa's main water consumer is agriculture, which often results in unwanted wastage through evaporation and runoff.

There are 63 transboundary river basins in Africa, covering 64 percent of the continent's land area containing 93 percent of its total surface water resource (UNEP, 2010). River basin commissions are responsible for managing these shared resources and the erection of large dams on both local and international rivers, which are used for irrigation and to supply water to big cities. Africa also has transboundary aquifers, mainly found in zones of high-water demand. Some transboundary aquifers, such as the Nubian Sandstone Aquifer System, contain non-renewable water that has been stored for a long time. The water demand that results from population increase and stress induced by climate change may increase aquifer users and rates of depletion (UNEP, 2016b).

A wide range of wetlands types is found in Africa, including natural and constructed freshwater marshes, river floodplains, swamps and peatlands, as well as estuaries and coastal lagoons. Constructed wetlands are designed for the treatment of wastewater from settlements and mining, while natural wetlands are under immense pressure from human activities, including wastewater discharge from agriculture, settlements and industry. In South Africa, for example, wetlands are used for the treatment of mine-water pollution in the gold-mining areas of Witwatersrand (UNEP, 2016b).

Mangrove forests, another threatened land-use type, inhabit many of the saline and brackish coastal and marine areas of the continent's coastline. In East Africa, stretching from the coastal cities of Kismayu in Somalia to Maputo in Mozambique; on the West African coastline stretching from northern Angola to the northern limit of Tidra Island in Mauritania. Altogether, the mangrove forests cover an area of 1.7 million ha. Mangroves are threatened by overharvesting for fuelwood, timber and charcoal, conversion of land including agriculture, aquaculture, infrastructure development, tourism and salt production, pollution, increased sedimentation and changing hydrology (UNEP, 2016b).

Standing back from these figures, UNEP concludes that a significant share of the continent's natural resources are used unsustainably with some lost through illegal activities, which implies that the stream of benefits generated from these resources is being reduced over time (UNEP, 2016b). This has serious implications for the long-term wellbeing of the population, as natural capital accounts for between 30 percent and 50 percent of total wealth. The GEO-6 Regional Assessment for Africa sums up the current state of these issues: the environment is deteriorating faster than previously thought, emphasising that African governments must act faster to reverse the worst trends (UNEP, 2016b). Africa's natural capital is integral to the 
economic growth of the continent, which hinges on its sustainable management. This is key to the transition to a wellbeing economy that will benefit all of Africa's population and its ecological underpinning.

\section{Applying a social-ecological systems approach to sustainable food}

The Africa Regional Overview of Food Security and Nutrition stated that the number of undernourished people on the continent had increased mainly due to the impact of climate change and conflict requiring an urgent need to build affected communities' resilience and to find peaceful solutions that strengthen food security (FAO, 2017). The impact of adverse climatic conditions, such as repeated droughts (often linked to the El Niño phenomenon) resulting in poor harvests and the loss of livestock, was of particular concern in the context of ecosystem services and building adaptive strategies in the face of rapid change. This was confirmed by the recent multi-agency publication, The State of Food Security and Nutrition in the World. This publication argues that 'the number of people who suffer from hunger has been growing over the past three years, returning to levels from a decade ago' (FAO et al., 2018:xiii). The situation is worsening in most regions of Africa with climate variability and extremes are a key driver of severe food crises.

Beyond climate and conflict, food and nutrition security are strongly predicated upon ecological resilience (International Panel of Experts on Sustainable Food Systems [IPES-Food], 2016; UNEP, 2016a). Natural resources are heavily impacted by changes in population numbers, wealth, urbanisation and associated changes in human behaviour toward food consumption. The ultimate causes of habitat loss in Africa are human population growth and the resulting demand for space, food and other resources; widespread poverty; dependence on natural resources; and economic pressures to increase exports, especially agricultural produce, timber and minerals (UNECA, 2011:51). Population and income growth will drive food demand in the coming decades; nearly 80 percent more meat, almost 60 percent more cereals, and one-third as many roots and tubers will be required by 2050 , at significantly higher food prices and with adverse consequences for the world's poor and vulnerable populations (Rosegrant et al., 2008).

Population growth will also have significant implications for building resilient social-ecological systems. Population growth in Africa is likely to continue to put pressure on food, land and water resources. The global population estimated at 7.6 billion by mid-2017, 1.3 billion African, is anticipated to grow with 2.2 billion people by 2050. It is estimated that 1.3 billion, more than half the global growth, will be added in Africa (UN, 2017). The geography and demography of Africa are, therefore, likely to change considerably in the next few decades. The so-called 'youth bulge', expected to reach over 830 million in Africa by 2050, will add to this 
pressure (Chatterjee \& Mahama, 2017). Not only will the number of mouths to feed increase, but many will also migrate to urban centres in search of employment and opportunities. This will change the dynamics of rural areas, particularly concerning the supply of labour and the ratio of producers to consumers.

With such change, shifts in consumer preference will occur, leading to a demand for convenience and ready-prepared foods that require little or no energy for preparation. There is now a trend towards the homogenisation of diets and the greater intake of calories, animal protein and fat, and ultra-processed foods that are high in sugar, salt and fat (Cook, 2018). Urban living associated with changes in activity and dietary patterns is part of a nutrition transition - a simultaneous emergence of challenge in rising levels of overweight, obesity and related noncommunicable diseases along with continuous problems of undernutrition and micronutrient deficiencies (Bray \& Popkin, 1998).

As the African population continues to grow and natural resources become scarcer, the need to shift towards an environmentally responsible, socially accountable, more equitable, and 'greener' economy becomes increasingly necessary. This is exemplified in the relationship of the social-ecological system that is the African food system. The International Panel of Experts on Sustainable Food Systems (IPES-Food) argued in a 2016 report, From Uniformity to Diversity, that we need a fundamentally different model of agriculture and to shift the centre of gravity. They stressed the need to transition to agroecological production systems stating, 'This transition is viable and necessary whether the starting point is highly specialized industrial agriculture or forms of subsistence farming in poor, developing countries'. Similarly, Biodiversity maintained that 'food systems need to be reformed so that they nourish people while nurturing the environment' (Frison; IPES-Food, 2016). They argue that agricultural biodiversity is a source of nutritious and culturally acceptable foods often adapted to local and low-input agricultural systems and a source of important traits for breeding resilient, nutritious crops and animal breeds.

UNEP's 2016 Food Systems and Natural Resources called for 'A fundamental transformation of our food systems ... if we are to meet future demands of food and quality of life for present and future generations' (UNEP, 2016a:14). Echoing this, the FAO 2017 report on the future of food and agriculture declares:

High-input, resource-intensive farming systems, which have caused massive deforestation, water scarcities, soil depletion and high levels of greenhouse gas emissions, cannot deliver sustainable food and agricultural production. [We need] innovative systems that protect and enhance the natural resource base, while increasing productivity. [We need] a transformative process towards 'holistic' approaches, such as agroecology, agro-forestry ... and conservation agriculture, which also build upon indigenous and traditional knowledge. (FAO, 2017:xi) 
A recent IPES-Food report, Unravelling the Food-Health Nexus, stressed the urgency of reforming food and farming systems on the grounds of protecting human health: 'The health impacts of food systems are interconnected, self-reinforcing, and complex - but we know enough to act (IPES-Food, 2017:1).

A key question emerging from these reports is how can Africa practically move towards these stated solutions for a sustainable food system as an example of a resilient social-ecological system? An important opportunity lies in the application of social-ecological systems theory. Social-ecological resilience is the capacity to adapt or transform in the face of change, particularly unexpected change, in socialecological systems in ways that continue to support human wellbeing (Chapin et al., 2010). Social-ecological systems theory draws on systems ecology and complexity theory - the study of how large-scale complex, organised, and adaptive behaviour can emerge from relatively simple interactions among individuals. Complex behaviours are embedded in social-ecological systems, such as nonlinearities, feedbacks, the existence of thresholds, the potential for alternative stable states and self-organisation (Norberg \& Cumming, 2008). Complex adaptive systems can be distinguished from other complex systems by their capacity to respond to their environment through self-organisation, learning and reasoning. These (social and ecological) agents often interact in unplanned and unpredictable ways which underlie the emergence of broad-scale patterns that feedback on the system and influence the interactions of the agents (Levin et al., 2013). The study of complex adaptive systems is, therefore, directly relevant to understanding the environment in which society is embedded and the problems that may arise.

Living with such complexity and uncertainty requires resilience-building approaches to management and governance of social-ecological systems. Echoing the first section of this chapter, this approach relies on realising that people and nature are interdependent systems, conceptualising this coupling and relating it to human wellbeing and sustainability. The field of development research traditionally treated the environment as a factor contributing to human wellbeing, which meant that natural resources were focused on one at a time to minimise impacts on the environment (Folke, Biggs, Norström, Reyers \& Rockström, 2016). This way of relating humans to the environment was reflected in the Millennium Development Goals. However, a need for a deeper integration with the social science featuring the social dynamics and features linked to the environmental challenges led to the Millennium Ecosystem Assessment (MEA), which represents a paradigm shift in the human-nature relationship: from protecting the environment and conserving biodiversity to the challenge of stewardship of ecosystems and diversity and their services for human wellbeing (MEA, 2005). 
Emerging knowledge, techniques and best practices in sustainable development

The nature-based solutions concept emerged in the late 2000s when international organisations searched for solutions to use nature to address societal challenges while protecting natural ecosystems and biodiversity and improving sustainable livelihoods. This concept is increasingly used by the International Union for Conservation of Nature (IUCN), the European Commission (EC) and other international organisations as well as in the scientific literature. Ecosystem-based adaptation (EbA), which involves the conservation, sustainable management and restoration of ecosystems to help people adapt to the impacts of climate change, is a nature-based solution that harnesses biodiversity and ecosystem services to build resilience to climate change. It has become increasingly more popular to construct wetlands, urban lakes and restore natural streams to recreate natural drainage and filter systems and restore and recover development conditions (Jato-Espino, Sañudo-Fontaneda \& Andrés Valeri, 2019)

For us to understand the ecological resilience of a system we need to understand and consider various ecological components as well as human influences. Natural environment means climate, natural resources, plant and animal life, topography, and natural phenomenon. The biotic and abiotic components not only provide us with the water we drink, the food we eat, but also regulate important cycles in nature. These ecological components are closely linked and intertwined with the social components, the human dimension in its diverse facets, including the economic, political, technological and cultural. Together they form a socialecological system, a complex adaptive system (Levin et al., 2013), a concept that emphasizes the human-in-nature perspective.

The social-ecological systems approach emphasizes the role that people, communities, economies, societies, and cultures play in the natural environment. These social components interact with and are inhabitants of the environment in which they depend on and are shaped by. Social-ecological system analysis presents a new way of thinking about the relationships between people and nature. This is based on the metaphor of resilience, defined by Folke et al. (2016), as the potential of a system to absorb disturbance and re-organise. Resilience is increasingly conceptualised not only as a property of social-ecological systems but also as an approach for managing these systems to ensure they continue to sustain human wellbeing amidst ongoing change and disturbance. 


\section{Ecosystem-based adaptation}

Ecosystem-based adaptation is a nature-based solution that uses biodiversity and ecosystem services to support communities to adapt and build resilience in the face of disturbance. Ecosystem-based adaptation uses the range of opportunities for sustainable management, conservation, and restoration of ecosystems to increase the resilience and reduce the vulnerability of ecosystems and people. According to the Convention on Biological Diversity (CBD), EbA is an approach to sustainable development that contributes to three outcomes: socio-economic benefits, climate change adaptation and biodiversity conservation (Midgley, Marais, Barnett \& Wågsæther, 2012). The intersection between these three spheres is what separates EbA from other approaches, such as community-based adaptation (CBA), climate change integrated land-use strategies (CLICS) or community-based natural resource management (CBNRM). EbA has a range of co-benefits including conservation of threatened species, livelihood benefits, sustainable utilisation of natural resources and the maintenance of ecosystem services such as water and food security (Convention on Biological Diversity [CBD], 2009).

South Africa's biodiversity and climate change policy provides clear support for the development of a coordinated programme of work on EbA, as part of an overall adaptation strategy envisaged in the National Climate Change Response White Paper (Department of Environmental Affairs [DEA], 2012). In response to the white paper, the 2013 Long-Term Adaptation Scenarios Flagship Research Programme (LTAS) highlights the 'potential for ecological infrastructure to provide ecological benefits and assist in achieving development aspirations across sectors, building resilience of South Africa's natural systems, working landscapes and open spaces to support economic sectors and local livelihoods under future climate conditions' (DEA, 2013:17). EbA projects are been implemented in many provinces of South Africa. These are documented in the NCCR database, hosted by the DEA.

Ecosystem-based adaptation projects are also well underway in other African countries, including Zambia where small-scale farmers are offered economic incentives for improved land management and are assisted in high-end organic food markets (Midgely et al., 2012). This EbA project maintains ecosystem services essential for agriculture, reducing pressure on natural systems and supporting diverse rural livelihood strategies.

\section{Key policy and strategic issues for African countries}

Underpinning an economic trajectory that will lead to a continent-wide wellbeing economy comes with important challenges, not least of which is the need to reduce 
the region's ecological footprint and safeguard the life-support system provided by healthy land, water, air and biodiversity.

Ecosystem-based adaptation is strongly promoted in the international policy arena. It is recognised under several multilateral environmental agreements for its ability to offer co-benefits in helping society adapt to changes, including climate change. The $\mathrm{CBD}$ has provided specific direction on $\mathrm{EbA}$ to support the United Nations Framework Convention on Climate Change (UNFCCC). The CBD's Strategic Plan for Biodiversity (2011-2010) and the Aichi Targets offer further support for EbA under Strategic Goal D which is to 'enhance the benefits to all from biodiversity and ecosystem services' (CBD, 2010:9). The UNFCCC similarly recognise the role of healthy, intact ecosystems in providing valuable services such as food, clean water, flood and erosion control. It provides national action plans and national adaptation programmes of action for least developed countries.

Similarly, the African Resilient Landscapes Initiative (ARLI) facilitated by the New Partnership for Africa's Development (NEPAD) emphasises forest and ecosystem restoration, biodiversity conservation, climate-smart agriculture, and rangeland management as key approaches towards nature-based solutions (NEPAD, 2017). Endorsed by the AU in October 2015, the ARLI and its supporting initiatives are contributing to improved soil fertility and food security, improve access to clean water, combat desertification, increase biodiversity and habitat, create green jobs, bolster economic growth and livelihood diversification, and increase the capacity for climate change resilience and adaptation (World Bank, 2015). The resilience of ecosystems thus cascades downwards to underpinning human wellbeing. A key example of this is the agri-food system.

Agricultural biodiversity is vital to the functioning of agroecosystems, to ensure food and nutrition security and to cope with the challenges of climate change. Yet the agricultural biodiversity of Africa is currently at risk as agricultural landscapes become increasingly simplified and the number of crops, crop varieties and animal breeds on farms decline (Rockström et al., 2009). The heavy reliance on this narrow range of food brings long-term risks for agricultural production, biodiversity, livelihoods and nutrition while undermining the ability of agriculture to adapt to climate change (Zimmerer, 2010). African farming systems can avoid exacerbating this through building on a fundamentally different model of agriculture based on diversifying farms and farming landscapes, replacing chemical inputs, optimising biodiversity and stimulating interactions between different species, as part of holistic strategies to build long-term fertility, healthy agro-ecosystems and secure livelihoods (IPES-Food, 2016). 
Diversified agro-ecological systems can also pave the way for diverse diets and improved health as recent evidence from across countries in Africa and South Asia including rural Ethiopia, Mozambique, Tanzania, Uganda and Zambia reveals (Carletto, Ruel, Winters \& Zezza, 2015; Kumar, Harris \& Rawat, 2015; Shively \& Sununtnasik, 2015). Agricultural diversity has been linked specifically to increased consumption of a range of key nutritional elements often missing in diets and based around staple cereal crops. The consumption of legumes, fruits and vegetables was found to be strongly associated with greater farm diversity in Malawi (Jones, Shrinivas \& Bezner-Kerr, 2014), and data from Zambia indicates that there was a strong positive association between production diversity and dietary diversity (Kumar et al., 2015).

These findings have profound implications across national boundaries, underlining the need for holistic, innovative, and collaborative solutions, policies and strategies that promote agro-biodiversity. Key to this is recognition of the local crop varieties, animal breeds and underutilised crops in Africa that could be promoted and maintained, adjusting extension services and fostering synergies between scientific and local knowledge. Indeed, biocultural heritage and traditional knowledge underpin much of the remaining agricultural biodiversity in Africa and should be nurtured, including by protecting the rights of women.

The box that follows presents four case studies illustrating the building of socialecological resilience in Africa. 


\section{Box 2.1: Case studies illustrating the building of social-ecological resilience in Africa}

\section{Livelihood diversity and redundancy in coastal communities in East Africa}

An important example of social-ecological resilience emerges from the coast of East Africa where households often engage in small-scale fisheries as part of a diverse livelihood portfolio including working in tourism, agriculture or casual labour. Households who have a portfolio of options tend to be more resilient, particularly if different livelihood activities are not affected by the same disturbances. For example, in households with diverse livelihood portfolios, fishing activities can continue when the tourism sector suffers low numbers of tourists due to global perceptions of security. It has been shown in Kenya, Tanzania, the Seychelles, Mauritius and Madagascar that coastal fishers are more likely to leave a fishery in response to declining catches if they come from households with more diverse livelihood portfolios.

\section{Avoiding poverty traps in Tanzania}

While feedbacks can help keep a system in a desirable regime, they can also lock a system into an undesirable configuration. In drought-prone areas of Tanzania, population growth has increased the demand for crop production and reduced fallow times. This has led to the depletion of organic matter in the soil and a decrease in soil fertility. This, in turn, means that crop harvests are low, and that farmers have little or no surplus to sell, and therefore no money to buy fertilisers to restore or increase soil fertility. As a result, they become trapped in a vicious cycle of poverty. In these cases, it may be necessary to disrupt or weaken the feedbacks that lock the systems in an undesired configuration. In Tanzania, rainwater harvesting, and conservation tillage help restore soil fertility and reduce the impacts of drought.

\section{Foster complex adaptive systems thinking}

There are several examples of how complex adaptive systems thinking contributes to enhances the resilience of a system. In the Kruger National Park in South Africa, management has moved away from strategies to keep ecosystem conditions, such as elephant populations and fire frequencies, at a fixed level and instead allows them to fluctuate between specified boundaries. The use of threshold indicators provides managers with warning signals when a component of the system is approaching a critical point. The overall intention is to reduce human intervention (and investment) and increase the variety of ecosystems and habitat types.

\section{Polycentric governance}

Polycentric governance is well suited for the governance of social- ecological systems and ecosystem services because traditional and local knowledge stand a much better chance of being considered. This, in turn, improves sharing of knowledge and learning across cultures and scales. This is particularly evident in local and regional water governance, as in watershed management groups in Botswana, where polycentric approaches have facilitated participation by a broad range of actors and incorporation of local, traditional and scientific knowledge.

(Source: Biggs et al., 2012) 


\section{Conclusion}

In summary, sustainable development cannot be achieved without grounding on an ecological foundation, but one that is not separated from the human element. Nature no longer simply sets the context in which social interaction takes place. Similarly, the human enterprise is not an external disturbance acting upon an ecosystem (Schoon \& Van der Leeuw, 2015). The environment that underpins human wellbeing both responds to and influences a wide range of social, political and economic elements as well as the interactions between them. These interactions are intertwined with and ultimately framed by the capacity of the biosphere as part of the complex dynamics of the Earth system to sustain progress and development (Odum, 1989; Steffen, Broadgate, Deutsch, Gaffney \& Ludwig, 2015). In sum, human development cannot be decoupled from the environment.

Whilst the inherent uncertainty and diversity in potential futures across the continent makes it tenuous for a set of prescriptive policies to be established, policy decisions should aim to minimise environmental and developmental trade-offs and maximise Africa's ability to safeguard its natural capital effectively (UNEP, 2016b). To achieve sustainable development and reach global biodiversity targets, naturebased solutions, in particular, should be treated as integral to adaptation strategies at global, national and local levels. Indeed, as is made explicit throughout the chapters of this book, the low-carbon, climate-resilient choices in infrastructure, energy and food production, coupled with effective and sustainable natural resource governance are key to protecting the continent's ecological assets that underpin a continent-wide wellbeing economy. 


\section{References}

Biggs, R., Schlüter, M., Biggs, D., Bohensky, E., BurnSilver, S.B. et al. (2012). Towards principles for enhancing the resilience of ecosystem services. Annual Review of Environment and Resources 37: 421-448. https://doi.org/10.1146/annurevenviron-051211-123836

Bray, G.A. \& Popkin, B.M. (1998). Dietary fat intake does affect obesity! The American Journal of Clinical Nutrition 68(6): 1157-1173. https://doi.org/10.1093/ ajcn/68.6.1157

Carletto, G., Ruel, M., Winters, P. \& Zezza, A. (2015). Farm-level pathways to improved nutritional status: Introduction to the special issue. The Journal of Development Studies 51(8): 945-957. https://doi.org/ 10.1080/00220388.2015.1018908

Chapin III, F.S., Carpenter, S.R., Kofinas, G.P., Folke, C., Abel, N. et al. (2010). Ecosystem stewardship: Sustainability strategies for a rapidly changing planet. Trends in Ecology and Evolution 25:241-249. https://doi. org/10.1016/j.tree.2009.10.008

Chatterjee, S. \& Mahama, J.D. (2017). Promise or peril? Africa's 830 million young people by 2050. [Web log post]. https://bit.ly/2CKXzIZ [Accessed 10 September 2019].

Convention on Biological Diversity. (2009). Connecting biodiversity and climate change mitigation and adaptation: Report of the second ad hoc technical expert group on biodiversity and climate change. CBD Technical Series No. 41. Montreal Secretariat of the CBD.

Convention on Biological Diversity. (2010). The strategic plan for biodiversity 2011-2020 and the Aichi biodiversity targets. https://www.cbd.int/kb/record/ decision/12268 [Accessed 26 March 2019].

Cook, S. (2018). The spice of life: The fundamental role of diversity on the farm and on the plate. Discussion Paper. IIED and Hivos, London and The Hague. https://bit. ly/2IFzgCd [Accessed 12 September 2019].
Cumming, G.S., Allen, C.R., Ban, N.C., Biggs, D., Biggs, H.C. et al. (2015). Understanding protected area resilience: A multi-scale, social-ecological approach. Ecological Applications 25(2): 299-319. https://doi.org/10.1890/13-2113.1

Daily, G.C., Soderqvist, T., Aniyar, S., Arrow, K., Dasgupta, P. et al. (2000). Ecology. The value of nature and the nature of value. Science 289 (5478): 395-396. https://doi.org/10.1126/ science.289.5478.395

Department of Environmental Affairs. (2012). National climate change response white paper. https://www.gov.za/documents/ national-climate-change-response-whitepaper [Accessed 25 March 2019].

Department of Environmental Affairs. (2013). Long-term adaptation scenarios flagship research programme (LTAS) for South Africa. Pretoria, South Africa: DEA.

Folke, C., Biggs, R. Norström, A.V., Reyers, B. \& Rockström, J. (2016). Social-ecological resilience and biosphere-based sustainability science. Ecology and Society 21(3): 41. https://doi.org/10.5751/ES-08748210341

Food and Agriculture Organization of the United Nations. (2017). Regional overview of food security and nutrition in Africa 2017. The food security and nutrition-conflict nexus: Building resilience for food security, nutrition and peace. Accra: FAO. http:// www.fao.org/3/a-i7967e.pdf [Accessed 4 April 2019].

Food and Agriculture Organization of the United Nations. (2017). The future of food and agriculture: Trends and challenges. Rome: FAO.

Food and Agriculture Organization of the United Nations. (2018). The state of the world's forests 2018 - Forest pathways to sustainable development. Rome. Licence: CC BY-NC-SA 3.0 IGO. 
Food and Agriculture Organization of the United Nations, United Nations International Children's Emergency Fund, World Health Organization, World Food Programme, International Fund for Agriculture Development et al. (2018). The state of food security and nutrition in the World 2018. Building climate resilience for food security and nutrition. Rome, FAO

Frison, A.; IPES-Food. (2016). From uniformity to diversity: a paradigm shift from industrial agriculture to diversified agroecological systems. Louvain-la-Neuve, Belgium: IPES. https://doi.org/10.5958/09761926.2016.00033.4

Funk, C.C., Dettinger M.D., Michaelsen, J.C., Verdin, J.P., Brown, M.E. et al. (2008). Warming of the Indian Ocean threatens eastern and southern African food security but could be mitigated by agricultural development. Proceedings of the National Academy of Sciences 105(32): 11081-11086. https://doi.org/10.1073/ pnas.0708196105

International Panel of Experts on Sustainable Food Systems. (2017). Unravelling the food-health nexus: Addressing practices, political economy, and power relations to build healthier food systems. The Global Alliance for the Future of Food and IPES-Food.

Jato-Espino, D., Sañudo-Fontaneda, L.A. \& Andrés Valeri, V.C. (2019). Green infrastructure: Cost-effective nature-based solutions for safeguarding the environment and protecting human health and wellbeing. In: C.M. Hussain (Ed.), Handbook of environmental materials management. Cham, Switzerland: Springer. https://doi. org/10.1007/978-3-319-73645-7_46

Jones, A., Breuning-Madsen, H., Brossard, M., Dampha, A., Deckers, J. et al. (Eds). (2013). Soil atlas of Africa. Luxembourg: European Commission Publication Office of the European Union.

Jones, A.D., Shrinivas, A. \& Bezner-Kerr, R. (2014). Farm production diversity is associated with greater household dietary diversity in Malawi: Findings from nationally representative data. Food Policy 46: 1-12. https://doi.org/10.1016/j. foodpol.2014.02.001

Kumar, N., Harris, J. \& Rawat, R. (2015). If they grow it, will they eat and grow? Evidence from Zambia on agricultural diversity and child undernutrition. The Journal of Development Studies 51(8): 1060-1077. https://doi.org/10.1080/0022 0388.2015.1018901

Levin, S., Xepapadeas, T., Crepin, A-S., Norberg, J., de Zeeuw, A. et al. (2013). Social-ecological systems as complex adaptive systems: Modeling and policy implications? Environment and Development Economics 18(2): 111-132. https://doi.org/10.1017/ S1355770X12000460

McCartney, M.P., Masiyandima, M. \& Houghton-Carr, H.A. (2005). Working wetlands: Classifying wetland potential for agriculture. Research Report 90. Colombo, Sri Lanka: International Water Management Institute (IWMI).

Midgley, G., Marais, S., Barnett, M. \& Wågsæther, K. (2012). Biodiversity, climate change and sustainable development - harnessing synergies and celebrating successes. Final Technical report, January 2012. South African National Biodiversity Institute, Conservation South Africa, Indigo Development and Change, with funding from the World Bank. https://bit.ly/2Vw3PiT [Accessed 15 September 2019].

Millenium Ecosystem Assessment. (2005). Ecosystems and human wellbeing (Vol. 5). Washington, DC: Island Press.

Nesshöver, C., Assmuth, T., Irvine K.N., Rusch, G.M., Waylen, K. et al. (2017). The science, policy and practice of nature-based solutions: An interdisciplinary perspective. Science of the Total Environment 579: 1215-1227. https://doi.org/10.1016/j. scitotenv.2016.11.106 
New Partnership for Africa Development. (2017). 2017 NEPAD annual report. https://www.growafrica.com/ resources/2017-nepad-annual-report [Accessed 12 September 2019].

Norberg, J. \& Cumming, G.S. (Eds). (2008). Complexity theory for a sustainable future. New York: Columbia University Press.

Odum, E.P. (1989). Ecology and our endangered life-support systems. Sunderland, MA: Sinauer Associates.

Ostrom, E. (1990). Governing the commons: The evolution of institutions for collective action. Cambridge, UK: Cambridge University Press. https://doi.org/10.1017/ CBO9780511807763

Rockström, J., Steffen, W., Noone, K., Persson, Å., Chapin, F.S. et al. (2009). Planetary boundaries: Exploring the safe operating space for humanity. Ecology and Society 14(2): Art. 32. https://doi. org/10.5751/ES-03180-140232

Rosegrant, M.W., Ringler, C., Msangi, S., Sulser, T.B., Zhu, T. et al. (2008). International model for policy analysis of agricultural commodities and trade (IMPACT): Model description.

Washington, DC: International Food Policy Research Institute. https://bit. ly/35me7Xp [Accessed 23 April 2018].

Schoon, M. \& van der Leeuw, S. (2015). The shift toward social-ecological systems perspectives: insights into the humannature relationship. Natures Sciences Sociétés 23(2): 166-174. https://doi.org/10.1051/ nss/2015034

Shawa, P. (2010). Deforestation in Mwekera National Forest No. 6: An ethical evaluation. Master's dissertation, University of Zambia, Lusaka.

Shively, G. \& Sununtnasik, C. (2015). Agricultural diversity and child stunting in Nepal. The Journal of Development Studies 51(8): 1078-1096. https://doi.org/10.108 0/00220388.2015.1018900
Steffen, W., Broadgate, W., Deutsch, L., Gaffney, O. \& Ludwig, C. (2015). The trajectory of the Anthropocene: The great acceleration. The Anthropocene Review 2:81-98. https://doi. org/10.1177/2053019614564785

United Nations. (2017). The sustainable development goals report 2017. New York: UN. https://bit.ly/2tyblvg [Accessed 15 September 2019]. https://doi. org/10.18356/3cff8bc0-en

United Nations Development Programme. (2012). Africa human development report 2012: Towards a food secure future. Geneva: UNDP. http://www.afhdr.org/the-report/ [Accessed 18 September 2019].

United Nations Environment Programme. (2010). Africa water atlas. Nairobi, Kenya: Division of Early Warning and Assessment (DEWA), UNEP. https://doi. org/10.18356/eaf6f03c-en

United Nations Environment Programme. (2013). Africa environment outlook 3: Our environment, our health. http:// www.unep.org/pdf/aeo3.pdf [Accessed 12 September 2019].

United Nations Environment Programme. (2016a). Food systems and natural resources. A Report of the Working Group on Food Systems of the International Resource Panel. Westhoek, H, Ingram J., van Berkum, S., Özay, L. \& Hajer, M.

United Nations Environment Programme. (2016b). GEO-6 regional assessment for Africa. Nairobi, Kenya: UNEP.

Williams, C.J.R., Kniveton, D.R. \& Layberry, R. (2010). Assessment of a climate model to reproduce rainfall variability and extremes over southern Africa. Theoretical and Applied Climatology 99(1/2): 9-27. https://doi.org/10.1007/ s00704-009-0124-y

World Bank. (2009, 16 June). World day to combat desertification 2009. [Web log post]. https://bit.ly/2pej97x [Accessed 18 September 2019]. 
World Bank. (2015). NEPAD launches initiative for the resilience and restoration of African landscapes. Press release, 6 December 2015. https://bit. ly/35nhLA6 [Accessed 23 March 2019].
Zimmerer, K.S. (2010). Biological diversity in agricultural and global change. Annual Review of Environment and Resources 35(1): 137-166. https://doi.org/10.1146/ annurev-environ-040309-113840 